\title{
ELOM-080 as Add-On Treatment for Respiratory Tract Diseases - A Review of Clinical Studies Conducted in China
}

\author{
Authors \\ Robert Fürst ${ }^{1}$, Betty Luong ${ }^{1}$, Jörn Thomsen ${ }^{2}$, Thomas Wittig ${ }^{2}$ \\ Affiliations \\ 1 Institute of Pharmaceutical Biology, Goethe University \\ Frankfurt, Germany \\ 2 G. Pohl Boskamp GmbH \& Co. KG, Hohenlockstedt, \\ Germany
}

Key words

ELOM-080, Myrtol, phytotherapy, clinical trials, respiratory tract diseases, mode of action

received February 22, 2019

revised May 18, 2019

accepted May 23, 2019

Bibliography

DOI https://doi.org/10.1055/a-0942-1993

Published online June 5, 2019 | Planta Med 2019; 85: 745754 (c) Georg Thieme Verlag KG Stuttgart · New York | ISSN 0032-0943

Correspondence

Prof. Dr. Robert Fürst

Institute of Pharmaceutical Biology, Goethe University

Frankfurt

Max-von-Laue-Str. 9, 60438 Frankfurt, Germany

Phone: + 496979829655 , Fax: + 496979876329655

fuerst@em.uni-frankfurt.de

\section{ABSTRACT}

ELOM-080, also known as Myrtol, represents a distillate of a mixture of 4 rectified essential oils: eucalyptus oil, sweet orange oil, myrtle oil, and lemon oil. ELOM-080 is an approved herbal medicinal product for the secretolytic therapy and facilitation of expectoration in acute and chronic bronchitis and for the secretolytic therapy of sinusitis. Its clinical efficacy has been reported by several randomized control trials. Interestingly, in the recent past, a considerable number of clinical studies on the use of ELOM-080 as add-on treatment of different respiratory tract diseases has been conducted and published in China. As these publications were only available in Chinese, the international attention in the literature was limited. Based on the translation of these studies into English, this review aims to provide a brief overview of the studies' major results, which contribute to the knowledge on the efficacy of ELOM-080 in the treatment of respiratory tract diseases: ELOM-080 was shown to be of great value as add-on treatment not only for the well-established indications bronchitis and sinusitis, but also for pharyngitis, asthma, chronic obstructive pulmonary disease, and, most importantly, otitis media. Besides this clinical evidence, this review also summarizes the great progress in deciphering the mode of action of ELOM-080 that has been made by Chinese publications.

$\begin{array}{ll}\text { ABBREVIATIONS } \\ \text { ADR } & \text { adverse drug reaction } \\ \text { CBF } & \text { ciliary beat frequency } \\ \text { COPD } & \text { chronic obstructive pulmonary disease } \\ \text { CT } & \text { computed tomography } \\ \text { FEV } 1 & \text { forced expiratory volume in } 1 \mathrm{~s} \\ \text { FEV1\% } & \text { FEV } 1 / F V C \text { in percent } \\ \text { FVC } & \text { forced vital capacity } \\ \mathrm{HL} & \text { hearing level } \\ \mathrm{MCC} & \text { mucociliary clearance } \\ \mathrm{PaCO}_{2} & \text { partial pressure of carbon dioxide } \\ \mathrm{PaO}_{2} & \text { partial pressure of oxygen }\end{array}$

\section{Diseases of the Respiratory Tract}

Infections are the most common diseases of the respiratory tract and are, thus, of utmost clinical importance. They result in high socioeconomic costs and substantial productivity losses due to sick leaves and hospitalization [1,2]. In most cases, these diseases are caused by viral infections, which can be succeeded by a secondary bacterial superinfection [2]. This complicates the medical treatment and, in particular, questions the prescription of antibiotics at an early stage of illness [3]. Furthermore, infections can be transmitted between upper and lower airways and thus need to be considered and treated as a single disease [4]. Apart from infections, long-term exposure of airways to environmental pollutions and smoking drastically increase the risk to develop chronic disorders, in particular chronic obstructive pulmonary disease (COPD) [5]. Aggravation of air quality in industrialized and urbanized areas in developing countries such as China leads to the epi- 
demic occurrence of chronic bronchitis or COPD already in children [6]. Consequently, these diseases raised the interest of Chinese physicians to apply adequate treatment and triggered research on the action and efficacy of herbal medicinal products in preclinical and clinical studies.

\section{ELOM-080}

ELOM-080, also known as Myrtol, represents a distillate of a mixture of 4 rectified essential oils: eucalyptus oil, sweet orange oil, myrtle oil, and lemon oil. In vitro and in vivo, the major monoterpenes 1,8-cineole, $(+)$-limonene and $(+)$ - $\alpha$-pinene are used as markers. Although these monoterpenes can be considered as biological marker substances, they unlikely encompass the full scope of pharmacologically active ingredients of ELOM-080 [7,8]. Enteric coated capsules containing ELOM-080 for oral administration are available in China under the trade name Myrtol Standardized Enteric Coated Soft Capsules (Children and Adults). Trade names of ELOM-080 in Germany are GeloMyrtol forte and Myrtol $120 \mathrm{mg}$. Pharmaceutical manufacturer of ELOM-080 is the company G. Pohl-Boskamp GmbH \& Co. KG, Hohenlockstedt, Germany. ELOM-080 is well established in the treatment of acute and chronic inflammatory diseases of the respiratory tract, in particular bronchitis and sinusitis, and is approved in many European and non-European countries. It has been shown to exert secretolytic, mucolytic, secretomotoric, anti-inflammatory, antioxidative, antimicrobial, and bronchospasmolytic effects [7,9-14]. The clinical efficacy and safety of ELOM-080 have been proven in prospective, large-scale, multicenter, double-blinded, randomized controlled trials that were planned, conducted, and reported according to the guidelines of Good Clinical Practice. ELOM-080 is recommended in German and international treatment guidelines [1521]. Furthermore, peer-reviewed scientific publications as well as independent organizations like the Cochrane Collaboration reviewed clinical studies on ELOM-080 with a positive vote [22-24].

\section{Search Strategy, Literature Evaluation, and Limitations of the Studies}

\section{Search strategy and literature evaluation}

A firsthand searching of journals and meeting abstracts dealing with respiratory medicine indicated that an increasing number of clinical studies with ELOM-080 have been conducted and published in China since 1996, the year in which ELOM-080 was launched in China. However, only few studies were translated and are, thus, rarely represented in the English scientific literature. In order to make these studies available to the English-speaking scientific community, the Medical Language Service $\mathrm{GmbH}$ in Gundelfingen, Germany, was asked for professional service in terms of literature research and the translation of the identified Chinese abstracts. Literature research was carried out by using either the Chinese or English search terms “标准桃金娘油” for “Myrtol standardized” and “吉诺通” for “GeloMyrtol” in PubMed, Google Scholar, and the China National Knowledge Infrastructure. In addition, the reference lists of all papers and reviews were checked for any other relevant articles. Available articles could be traced back to 1998, shortly after the product was launched in China.

In total, 52 articles of Chinese research groups were identified; 41 articles were available only in Chinese and 11 in English. In the case of clinical trials in the field of respiratory tract diseases (sinusitis, bronchitis including COPD, otitis media, pharyngitis, and asthma), only prospective and controlled studies with at least descriptive statistical analysis and stated inclusion and evaluation criteria were considered for this review. Additionally, experimental studies on mucociliary clearance were also included.

In sum, 18 articles did not meet the inclusion criteria: 6 studies with ELOM-080 as basic treatment in all groups, 2 studies without control, 5 studies in other indications, 1 pharmacokinetic study, and 4 experimental animal studies. Finally, 34 articles were assessed as eligible for this review: 25 clinical trials, 4 review articles, and 5 experimental studies on mucociliary clearance. Articles in Chinese language (in particular all included 25 studies) were translated into English by a native speaker, Betty Luong, from the Institute of Pharmaceutical Biology, Goethe University, Frankfurt, Germany. Of note, none of the clinical trials and with one exception [25] none of the experimental studies on mucociliary clearance were sponsored by the pharmaceutical manufacturer of ELOM-080. The trials were initiated, financed, and conducted solely by the respective Chinese investigators. ELOM-080 was applied orally (capsules) throughout all included clinical trials.

Depending on the indication, the evaluation of clinical efficacy differed between the studies. Main symptoms assessed for sinusitis studies were nasal congestion, discharge, and mucus production. In bronchitis and COPD studies, main symptoms were cough, sputum, pulmonary function, and, for COPD only, blood gas values. Otitis media was characterized by symptoms such as aural fullness and tinnitus and audiological measurements like pure tone audiometry and acoustic impedance tests. Post nasal drip and pharyngitis were assessed by cough, sputum, foreign body sensations, throat pain, and dryness. The total therapeutic efficacy of the treatment group and the control group, which is defined as cured and significantly improved cases of each group in percent, is provided in $>$ Table 1. Measurement parameters taken from the trials are presented as mean \pm standard deviation.

\section{Limitations}

This review encompasses mainly observational studies and smallscale interventional trials with explorative designs. All articles followed the general structure of trial reports including abstract, objectives, patients, methods, results, discussion, and references. Nonetheless, the articles were most often short and consisted of only 2-3 printed pages. As a result, detailed information was usually not provided. It was not reported whether the studies were registered in (Chinese) trial registers or whether ethic committees were involved. Adequate techniques of randomization or allocation concealment were not described. Outcome parameters were predominantly relative pre-post changes of symptoms (improvement rates) or as otherwise specified in $>$ Table $\mathbf{1}$. Reported results were focused on efficacy/effectiveness data that are based on individually defined efficacy categories depending on score values or measurement parameters used in each trial. Although 
- Table 1 Overview of reviewed studies, indications, co-medications, and exposure data (1253 patients with ELOM-080; in total 2450 patients). Total therapeutic efficacy is defined in the different clinical trials as cured and significantly improved cases.

\begin{tabular}{|c|c|c|c|c|c|c|}
\hline Indication & $\begin{array}{l}\text { Reference } \\
\text { (first author, year) }\end{array}$ & $\begin{array}{l}\text { Permitted co-medication } \\
\text { in all groups }\end{array}$ & $\begin{array}{l}\text { Applied only in } \\
\text { control group }\end{array}$ & $\begin{array}{l}\text { Number of pa- } \\
\text { tients (ELOM- } \\
080 / \text { control) }\end{array}$ & $\begin{array}{l}\text { Therapeutic } \\
\text { outcome of } \\
\text { ELOM-080 (\%) }\end{array}$ & $\begin{array}{l}\text { Therapeutic } \\
\text { outcome of } \\
\text { control (\%) }\end{array}$ \\
\hline \multicolumn{7}{|c|}{ Treatment of upper respiratory tract diseases } \\
\hline Pharyngitis & Zhang, 2009 [26] & $\begin{array}{l}\text { TCM product (Zhen Huang } \\
\text { capsules) }\end{array}$ & - & $138 / 148$ & 84.1\# & 64.2 \\
\hline \multirow[t]{7}{*}{ Sinusitis } & Chen, 2004 [27] & $\begin{array}{l}\text { TCM product (Bi Yuan Shu), } \\
\text { anti-infectives, nasal drops }\end{array}$ & - & $32 / 30$ & $90.6^{*}$ & 66.7 \\
\hline & Nai, 2008 [28] & $\begin{array}{l}\text { Azithromycin, fluticasone, } \\
\text { and oxymetazoline (nasal) }\end{array}$ & - & $43 / 42$ & $95.3^{*}$ & 78.6 \\
\hline & Zhou, 2010 [29] & Azithromycin & - & $75 / 75$ & $94.7^{*}$ & 80.0 \\
\hline & Li, 2014 [30] & Azithromycin & - & $90 / 90$ & $91.1^{*}$ & 75.6 \\
\hline & Wu, $2011[31]$ & Ephedrine (nasal) & Chlorphenamine & $41 / 28$ & $78.1^{\Delta}$ & 39.3 \\
\hline & Xia, 2008 [32] & $\begin{array}{l}\text { Anti-infectives, nasal drops, } \\
\text { irrigation of sinuses }\end{array}$ & - & $40 / 38$ & $90.0^{*}$ & 68.4 \\
\hline & Chen, 2001 [33] & $\begin{array}{l}\text { Penicillin (acute cases), } \\
\text { gentamicin (chronic cases) }\end{array}$ & $\begin{array}{l}\text { Sulfamethoxazole, sodi- } \\
\text { um chloride nasal drops }\end{array}$ & $80 / 80$ & $\begin{array}{l}93.3 \text { (chronic)* }^{*} \\
95.0 \text { (acute) }^{*}\end{array}$ & $\begin{array}{l}71.1 \text { (chronic) } \\
85.0 \text { (acute) }\end{array}$ \\
\hline \multicolumn{7}{|c|}{ Treatment of lower respiratory tract diseases } \\
\hline $\begin{array}{l}\text { Bronchitis, } \\
\text { acute }\end{array}$ & Li, 2004 [34] & $\begin{array}{l}\text { Acetaminophen, procaterol, } \\
\text { antibiotics }\end{array}$ & Carbocysteine & $33 / 30$ & $97.0^{*}$ & 80.0 \\
\hline \multirow{3}{*}{$\begin{array}{l}\text { Bronchitis, } \\
\text { chronic }\end{array}$} & Zhang, 2002 [35] & Unspecified anti-infectives & Bromhexine & $34 / 32$ & $73.5^{*}$ & 43.8 \\
\hline & Gao, 2008 [36] & $\begin{array}{l}\text { Antibiotics, bronchospasmo- } \\
\text { lytics, oxygen supply }\end{array}$ & Bromhexine & $42 / 42$ & $95.1^{*}$ & 78.6 \\
\hline & Gan, 2009 [37] & $\begin{array}{l}\text { Unspecified anti-infectives and } \\
\text { bronchospasmolytics }\end{array}$ & - & $30 / 30$ & $93.3^{*}$ & 76.7 \\
\hline \multirow[t]{2}{*}{ COPD } & Xu, 2009 [38] & Unspecified & Ambroxol & $50 / 50$ & $97.4^{*}$ & 73.7 \\
\hline & Wen, 2011 [39] & Antibiotics, oxygen supply & - & $42 / 44$ & Abs. changes*1 & Abs. changes ${ }^{1}$ \\
\hline Asthma & Gao, 1998 [40] & $\begin{array}{l}\text { Salbutamol, beclomethasone, } \\
\text { oxygen, aminophylline, anti- } \\
\text { biotic (plus dexamethasone in } \\
\text { severe cases) }\end{array}$ & - & $38 / 36$ & Abs. changes $* \Delta 2$ & Abs. changes ${ }^{2}$ \\
\hline \multicolumn{7}{|c|}{ Treatment of otitis media } \\
\hline \multirow[t]{8}{*}{ Otitis media } & Chen, 2002 [41] & $\begin{array}{l}\text { Dexamethasone and chymo- } \\
\text { trypsin injection into tympanic } \\
\text { cavity }\end{array}$ & Adenosine & $50 / 42$ & Audiometry* & Audiometry \\
\hline & Yu, 2002 [42] & Cefradine, prednisone & - & $36 / 34$ & $69.4^{3}$ & $52.9^{3}$ \\
\hline & Zhou, 2001 [43] & $\begin{array}{l}\text { Antibiotics, steroids, } \\
\text { ephedrine nasal drops }\end{array}$ & - & $35 / 20$ & $85.4^{*}$ & 54.2 \\
\hline & Tang, 2006 [44] & Antibiotics, prednisone & Decongestant nasal spray & $35 / 23$ & $86.5^{3}$ & $56.8^{3}$ \\
\hline & Li, 2008 [45] & $\begin{array}{l}\text { Ephedrine nasal drops, micro- } \\
\text { wave, Eustachian tube dilation, } \\
\text { tympanic puncture, fluid aspi- } \\
\text { ration, optional surgery }\end{array}$ & - & $40 / 39$ & $90.4^{*}$ & 81.7 \\
\hline & Xue, 2009 [46] & $\begin{array}{l}\text { Cefaclor, prednisone, optional } \\
\text { ephedrine nasal drops }\end{array}$ & - & $40 / 35$ & $87.2^{*}$ & 69.0 \\
\hline & Zhang, 2011 [47] & $\begin{array}{l}\text { Microwave, antibiotics, predni- } \\
\text { sone, furosemide, serrapep- } \\
\text { tase }\end{array}$ & - & $45 / 45$ & $98.3^{*}$ & 78.0 \\
\hline & Gu, 2011 [48] & Penicillin & - & $50 / 51$ & $96.5^{3}$ & $90.9^{3}$ \\
\hline
\end{tabular}




\begin{tabular}{|c|c|c|c|c|c|c|}
\hline Indication & $\begin{array}{l}\text { Reference } \\
\text { (first author, year) }\end{array}$ & $\begin{array}{l}\text { Permitted co-medication } \\
\text { in all groups }\end{array}$ & $\begin{array}{l}\text { Applied only in } \\
\text { control group }\end{array}$ & $\begin{array}{l}\text { Number of pa- } \\
\text { tients (ELOM- } \\
080 / \text { control) }\end{array}$ & $\begin{array}{l}\text { Therapeutic } \\
\text { outcome of } \\
\text { ELOM-080 (\%) }\end{array}$ & $\begin{array}{l}\text { Therapeutic } \\
\text { outcome of } \\
\text { control (\%) }\end{array}$ \\
\hline \multicolumn{7}{|c|}{ Preventive action } \\
\hline Otitis media & He, 2013 [49] & None & - & $30 / 30$ & $23.3^{\Delta 4}$ & $56.7^{\Delta 4}$ \\
\hline Sinusitis & Yan, 2005 [50] & $\begin{array}{l}\text { Cefmetazole, fluticasone, sa- } \\
\text { line nasal irrigation }\end{array}$ & - & $84 / 83$ & $\begin{array}{l}\text { Post-surgery } \\
\text { parameters }{ }^{*} \Delta 5\end{array}$ & $\begin{array}{l}\text { Post-surgery } \\
\text { parameters }\end{array}$ \\
\hline
\end{tabular}

data analysis included inferential statistics in 23/25 (92\%) studies (e.g., Student's t-test and 4-fold table $x^{2}$ test), the number of evaluated patients was not based on sample size estimation before study start. Basic treatment and co-medication such as antibiotics, expectorants, bronchodilators, or nasal drops were permitted in most of the trials and specified in > Table 1. Some co-medications were not in accordance with European therapy guidelines on the pharmacological treatment of the respective disease. Furthermore, it was not described how the test medications were provided to the patients. It is assumed that only commercial products were used. Compliance with test medications was not documented in the articles. Some of these limitations have also been stated in different Chinese meta-analyses [51-53].

\section{ELOM-080 in the Treatment of Upper Respiratory Tract Diseases}

\section{Pharyngitis}

In 2009, Zhang et al. [26] published their findings regarding the efficacy of ELOM-080 in patients (age: $12-75 \mathrm{y}$ ) suffering from pharyngitis. Both the control group (148 patients) and the treatment group (138 patients) received traditional oral Zhen Huang capsules (a complexly composed traditional Chinese medicine product). In the treatment group, ELOM-080 (300 mg) was additionally applied 3 times daily. Effectiveness rating was based on relieve of sore, dry and itchy throat, foreign body sensation, pharyngeal edema, and recovery of normal viscous secretion of the pharyngeal wall after a treatment period of $15 \mathrm{~d}$. The combined treatment resulted in a total efficacy of $84.1 \%$, whereas control group efficacy was significantly lower with $64.2 \%$ [26].

\section{Sinusitis}

The therapeutical effects of ELOM-080 in the treatment of chronic sinusitis were assessed in 5 clinical studies, which were all conducted with children. In a study by Chen [27], 62 children (age: 6-14 y) who suffered chronic sinusitis for 1-4 y were treated with a basic medication consisting of the oral herbal liquid Bi Yuan Shu (a complex traditional Chinese medicine product), anti-infective drugs, and nasal drops for $3 \mathrm{wk}$. The treatment group (32 patients) additionally received ELOM-080 $(120 \mathrm{mg}) 3$ times daily. Clinical symptoms such as nasal ventilation, nasal mucus, hypos- mia, nasal mucosal hyperemia, and edema were assessed before and after treatment and combined to a sum score. The efficacy in the control and treatment group were $66.7 \%$ and $90.6 \%$, respectively [27]. In 2008, Nai et al. [28] published the results of a clinical study with 85 children (age: 6-12 y) suffering from chronic sinusitis, which was diagnosed by symptoms and also by computed tomography (CT) scans of the sinuses. Basic treatment consisted of azithromycin, a nasal fluticasone spray, and oxymetazoline. The treatment group (43 patients) additionally received ELOM-080 (120 mg, 3 times a day). After 4 wk of treatment, the total efficacy was $95.3 \%$ in the ELOM-080 group, which was superior to the control group with 78.6\% [28]. Two more studies applied a combination of azithromycin as basic medication and ELOM-080 (2 and 3 times $120 \mathrm{mg}$ daily) in the therapy of chronic sinusitis, which, however, differed in the duration of treatment (2 wk [29] and 3 mo [30]). The trial performed by Zhou et al. [29] included 150 patients (5-14y), and the trial of Li [30] included 180 patients (7-14 y). In both studies, symptoms were assessed, and CT scans documented the state of sinus swelling. Despite different treatment periods, ELOM-080 significantly improved the total efficacy in both studies by about $15 \%$ points compared to the control group $(80.0 \%$ and $75.6 \%$ ) to values of $94.7 \%$ and $91.1 \%$, respectively $[29,30]$. Finally, the efficacy of ELOM-080 (120 mg twice daily) was compared to an antihistaminic treatment (chlorphenamine, 4 mg, 3 times daily) [31]. Both groups received a basic treatment of $1 \%$ ephedrine nasal drops over a period of 12 wk. Sixty-nine children in the age of 4-10 y were included into this study. Whereas the therapeutic efficacy (cured and significantly improved cases) in the chlorphenamine group (28 patients) was only $39.3 \%$, it significantly increased to $78.1 \%$ in the ELOM-080 group (41 patients). In addition, complete treatment failure occurred in only 1 patient (2.4\%) of the ELOM-080 group but was much higher in the chlorphenamine group (17.9\%) [31].

Xia et al. [32] published a study on the treatment of the sinusitis-associated post nasal drip syndrome in 78 children (age: 3$14 \mathrm{y}$ ). The basic medication for all patients lasted for $30 \mathrm{~d}$ and consisted of anti-infectives, nasal drops, and irrigation of nasal sinuses. The treatment group (40 patients) additionally received ELOM-080 (twice daily at the age of 3-6; 3 times daily at the age of 7-14). Treatment efficacy was assessed based on symptoms and radiological examinations. In the control group (38 patients), a total efficacy of $68.4 \%$ was achieved, whereas the ELOM-080 group reached a significantly higher value of $90.0 \%$ [32]. 
Chen and Chen [33] reported results from a study with 160 patients (age: 14-61 y) suffering from acute and chronic sinusitis patients. The treatment group (80 patients; 20 acute and 60 chronic sinusitis) received ELOM-080 three times daily (acute) or twice daily (chronic). The control group (also 80 patients; 20 acute and 60 chronic sinusitis) was medicated with $0.96 \mathrm{~g}$ sulfamethoxazole twice daily and $1 \%$ sodium chloride nasal drops $3-$ 4 times a day. Furthermore, both the control and treatment group received the following medication: acute cases were treated with penicillin and physiological saline for $3 \mathrm{~d}$, and chronic cases were treated with frontal sinus irrigation with gentamicin once or twice per week. Total efficacy assessed as relieve of symptoms like nasal congestion, headache, and turbinate swelling was $93.3 \%$ and 95.0\% in ELOM-080-treated chronic and acute cases, respectively, but lower in the control group with $71.1 \%$ and $85.0 \%$ [33].

\section{ELOM-080 in the Treatment of Lower Respiratory Tract Diseases}

Most of the studies focused on 3 diseases of the lower respiratory tract: acute bronchitis, chronic bronchitis, and COPD. As symptoms of chronic bronchitis and COPD overlap, clear diagnoses of the latter cannot always be guaranteed. Accordingly, a meta-analysis of ELOM-080 efficacy combined and evaluated studies on both diseases and concluded significantly higher cure or improvement rates of ELOM-080 treated patients compared to no or basic treatment [51]. In the following, studies on the treatment of lower respiratory tract diseases are reviewed in greater detail.

\section{Acute bronchitis}

Effects of ELOM-080 in therapy of acute and asthmatic bronchitis were studied in 63 children (age: 4-12y) who were randomly assigned to a treatment with ELOM-080 (age 4-6: $120 \mathrm{mg}$ twice a day; age 7-12: $120 \mathrm{mg}, 3$ times a day) or carbocysteine (30 mg/ kg bodyweight, 3 times daily) [34]. In both groups, optional treatment of fever (acetaminophen), asthma (procaterol hydrochloride), or increased white blood cells ( $\beta$-lactam antibiotics) was permitted. Changes of clinical symptoms like cough, sputum, and rales were assessed following a treatment period of 5-7 $d$ and revealed an efficacy of $97 \%$ for ELOM-080 (33 patients) compared to $80 \%$ for the active control (30 patients). In addition, the recovery time from fever and abnormal white blood cell counts was shortened in the treatment group [34].

\section{Chronic bronchitis}

In a pediatric study, 66 children (age: 4-10 y) with recurrent bronchitis were treated with either ELOM-080 $(120 \mathrm{mg}, 3$ times daily for $2 \mathrm{wk}$, then twice daily) or bromhexine hydrochloride ( $8 \mathrm{mg}$ 3 times a day) over a period of $1 \mathrm{mo}$, and the time until the symptoms disappeared was assessed [35]. Fever disappeared significantly faster in the treatment group (34 patients; $2.29 \pm 0.84 \mathrm{~d}$ until disappearance) than in the control group (32 patients; $3.84 \pm 1.08 \mathrm{~d}$ until disappearance), and the total efficacy was $73.5 \%$ compared to $43.8 \%$ in the control group after $1 \mathrm{y}$ of follow-up [35].
Adult patients (84; age: 19-57 y) with acute exacerbations of their chronic bronchitis received a 1-wk treatment with basic medication that encompassed antibiotics, bronchospasmolytic agents, and oxygen supply [36]. In addition, they were randomly distributed to the treatment group (42 patients), which received ELOM-080 (300 mg, 3 times daily) or to the control group (42 patients), which received bromhexine ( $16 \mathrm{mg}, 3$ times daily). Sputum significantly decreased within $3.0 \pm 1.3 \mathrm{~d}$ in the treatment group compared to $5.7 \pm 0.7 \mathrm{~d}$ in the control group. Similarly, a cumulative score, which integrated cough, expectoration, and the production and properties of sputum improved in $95.1 \%$ of ELOM-080-treated patients during the treatment but only in $78.6 \%$ patients of the control group. Initially, blood gas parameters $\left(\mathrm{PaO}_{2}\right.$ and $\left.\mathrm{PaCO}_{2}\right)$ did not differ between both groups but were significantly improved by ELOM-080 in comparison to the bromhexine treatment [36]: $\mathrm{PaO}_{2}$ strongly increased during the course of the trial from $50.50 \pm 3.23$ to $60.4 \pm 2.35 \mathrm{mmHg}$ in the treatment group and only slightly increased from $47.41 \pm 3.12$ to $53.1 \pm 2.21 \mathrm{mmHg}$ in the control group. $\mathrm{PaCO}_{2}$ strongly decreased from $55.21 \pm 2.14$ to $48.12 \pm 1.12 \mathrm{mmHg}$ in the treatment group and remained unchanged in the control group (56.41 \pm 1.09 and $55.02 \pm 2.12 \mathrm{mmHg}$ ).

Improvement of acute exacerbations of a chronic bronchitis was also observed in 60 elderly patients $(65-70 \mathrm{y})$ in a study by Gan and Cao [37]. The authors quantified the pulmonary function and the overall efficacy following a $20 \mathrm{~d}$ routine treatment (infection control, spasm relieve, correction of acid-base, or fluid-electrolyte imbalance) without further medication (30 patients) or in combination with ELOM-080 (300 mg, 3 times daily; 30 patients) randomly assigned to the 2 groups. The therapeutic efficacy in the treatment group (93.3\%) was significantly higher than in the control group (76.7\%). The pulmonary function measure forced vital capacity (FVC) increased in the treatment group from $2.04 \pm 0.72$ at the beginning of the trial to $2.34 \pm 0.73 \mathrm{~L}$ at the end of the study and from $2.13 \pm 0.66$ to $2.32 \pm 0.74 \mathrm{~L}$ in the control group. The forced expiratory volume in $1 \mathrm{~s}$ expressed as percentage of the FCV increased from $38.58 \pm 15.96$ to $44.36 \pm 15.37 \%$ in the treatment group and remained almost unchanged in the control group (34.36 \pm 13.8 to $36.72 \pm 12.7 \%$ ) [37].

\section{COPD}

Two meta-analyses that aimed to assess the efficacy of ELOM-080 in the treatment of COPD can be found in the Chinese scientific literature [52,54]. They differentiate between clinical trials with placebo or active control reference groups and conclude that both the symptom-based total efficacy as well as the recovery of pulmonary functions and the consequential improvement of blood gas parameters were higher following the treatment with ELOM080 compared to control treatment. In the following, 2 COPD studies are presented in detail: $\mathrm{Xu}$ and $\mathrm{Wu}$ [38] investigated the efficacy of ELOM-080 for the treatment of acute acerbations in 100 COPD patients. ELOM-080 $(300 \mathrm{mg}, 3$ times daily; 50 patients) was compared to ambroxol hydrochloride (30 mg, 3 times daily; 50 patients) in a treatment period of $2 \mathrm{wk}$. The treatment efficacy was assessed based on the symptoms cough and expectoration and on effects on the blood gas parameters $\mathrm{PaO}_{2}$ and $\mathrm{PaCO}_{2}$. Antibiotics were permitted for medication of acute exac- 
erbations. Compared to ambroxol, treatment with ELOM-080 resulted in a significantly higher relieve of symptoms ( $97.4 \%$ vs. $73.7 \%$ ) and recovery of the blood gas parameters [38]: $\mathrm{PaO}_{2}$ strongly increased from $68.0 \pm 11.8$ (start of the trial) to $82.5 \pm 12.0 \mathrm{mmHg}$ (end of the trial) in the treatment group and did not increase in the control group $(69.6 \pm 12.2$ vs. $70.0 \pm$ $12.8 \mathrm{mmHg}$ ). $\mathrm{PaCO}_{2}$ decreased from $48.5 \pm 9.8$ to $41.0 \pm$ $9.06 \mathrm{mmHg}$ in the treatment group and did not change in the control group $(47.8 \pm 9.5$ vs. $46.2 \pm 10.0 \mathrm{mmHg})$. In a 2 -wk trial, an elderly patient population (86 persons, $50-78 \mathrm{y}$ of age) with acute exacerbations of COPD received standard therapy consisting of antibiotics and oxygen supply [39]. The treatment group was additionally medicated with ELOM-080 (300 mg, 3 times daily). Criteria for treatment success were scale scores of clinical symptoms (cough, sputum and dyspnea), quality of life and quantification of blood gas parameters $\left(\mathrm{PaO}_{2}\right.$ and $\left.\mathrm{PaCO}_{2}\right)$, and pulmonary function $\left(\mathrm{FEV}_{1}\right)$. Clinical symptoms as well as the quality of life improved to a greater extend in the ELOM-080-treated group (42 patients) compared to patients who received only the standard therapy (44 patients). Physiological parameters of blood gas and pulmonary function significantly improved in both groups, but ELOM-080 enhanced the changes leading to a significantly better outcome when compared to the control [39]: $\mathrm{PaO}_{2}$ strongly increased from $64.8 \pm 6.6$ (trial start) to $80.0 \pm 7.2 \mathrm{mmHg}$ (trial end) in the treatment group. The increase observed in the control group was less pronounced $(63.4 \pm 5.2$ vs. $72.3 \pm$ $6.3 \mathrm{mmHg}$ ). $\mathrm{PaCO}_{2}$ decreased from $48.2 \pm 4.6$ to $41.6 \pm$ $4.3 \mathrm{mmHg}$ in the treatment group but only slightly decreased in the control group $(47.9 \pm 3.7$ vs. $45.0 \pm 3.9 \mathrm{mmHg})$. Moreover, in the treatment group, $\mathrm{FEV}_{1}$ rose from $1.26 \pm 0.08$ to $1.52 \pm 0.11 \mathrm{~L}$ but only slightly increased in the control group from $1.27 \pm 0.09$ to $1.36 \pm 0.11 \mathrm{~L}$.

\section{Asthma}

Seventy-four children (mean age: approximately $6.5 \mathrm{y}$ ) with acute asthma were treated with a basic inhaled medication of salbutamol and beclomethasone [40]. In moderate cases, this medication additionally included oxygenation, aminophylline, and antibiotics; in severe cases, dexamethasone was added to this therapeutic regime. Besides the basic medication, the treatment group (38 patients) additionally received $300 \mathrm{mg}$ ELOM-080 three times daily. The number of exacerbations and the time until panting and rales disappeared was assessed in both groups. Whereas no differences were obtained for the number of exacerbations in both groups, ELOM-080 treatment significantly reduced the mean time period until the disappearance of panting from 5.8 to $4.1 \mathrm{~d}$ and of whistling rales from 7.3 to $4.5 \mathrm{~d}$ [40].

\section{ELOM-080 in the Treatment of Otitis Media}

Our search in the Chinese literature revealed several clinical studies in which ELOM-080 was administered as add-on treatment in the context of otitis media. In 2013, 5 studies have been evaluated in a meta-analysis, which only revealed a tendency toward a beneficial effect of ELOM-080, since this effect was statistically not significant [53]. This was most likely due to the small number of studies included into this meta-analysis and the large variances of the effect sizes between these studies. In the following, the results of clinical trials on the efficacy of ELOM-080 in patients suffering from otitis media are summarized:

The study by Chen [41] included 92 patients (age: 8-72 y) suffering from secretory otitis media who received a basic treatment consisting of dexamethasone and chymotrypsin injection into the tympanic cavity. ELOM-080 (300 mg for adults, $120 \mathrm{mg}$ for children; 3 times daily) was applied as additional treatment for $15 \mathrm{~d}$ (treatment group, 50 patients). The control group (42 patients) received adenosine triphosphate tablets ( $40 \mathrm{mg}$ for adults, $20 \mathrm{mg}$ for children; 3 times daily). The therapeutic efficacy was assessed directly following the treatment and as a follow-up after 6 mo. At each time point, ELOM-080 treatment resulted in significantly better results of audiometric measurements: the mean air conduction threshold changed in the control group from $45 \pm 6 \mathrm{~dB}$ (start of trial) to $30 \pm 4 \mathrm{~dB}$ (end of trial) and in the treatment group from $45 \pm 6 \mathrm{~dB}$ to $21 \pm 8 \mathrm{~dB}$. The tympanogram peak measure changed in the control group from $-205 \pm 25 \mathrm{daPa}$ (start of trial) to $-102 \pm 10 \mathrm{daPa}$ (end of trial) and in the treatment group from $-210 \pm 20$ to $-80 \pm 15$ daPa. Moreover, the study also revealed a better total efficacy for tinnitus and aural fullness reduction with less relapses after 6 mo in the treatment group compared to the control group [41].

Yu and Zhang [42] treated 70 otitis media patients (age: 7$56 \mathrm{y}$ ) with oral cefradine ( 0.5 and $1 \mathrm{~g}, 3$ times per day, for children and adults, respectively) and prednisone (children: $5 \mathrm{mg}$ once per day; adults: $5 \mathrm{mg}$ twice per day) for a period of $10 \mathrm{~d}$. The treatment group (36 patients) additionally received ELOM-080 (children: 120 mg twice daily; adults: $300 \mathrm{mg}$ twice daily). This addon treatment with ELOM-080 improved the hearing threshold and the results of an acoustic impedance test with a final cure rate of $69.4 \%$ compared to $52.9 \%$ of the group that only received the basic medication [42].

Tympanograms were assessed as major read-out parameter in a 1-wk clinical study with 55 patients (age: 15-56y) comparing basic treatment (ephedrine nasal drops, antibiotics, and steroids) with an additional application of ELOM-080 (300 mg, 3 times daily) [43]. The tympanograms were recorded 1 and 2 wk after the treatment and shifted from initially type $B$ and $C$ to type $A$, which indicates a normalization of the middle ear function. The ratio of type A tympanogram after $1 \mathrm{wk}$ was $68.3 \%$ in the ELOM-080 group (35 patients) and $37.5 \%$ in the control group (20 patients). After 2 wk, the ratio was $85.4 \%$ in the ELOM-080 and $54.2 \%$ in the control group. Differences were statistically significant [43].

ELOM-080 (300 mg, 2 times daily) was applied for $7 \mathrm{~d}$ in combination with budesonide nasal spray and basic medication including antibiotics and prednisone in a study with 58 patients with a mean age of $37 \mathrm{y}$. Efficacy was assessed using impedance and pure tone audiometry for the treatment group (35 patients) compared to the control group (23 patients) receiving basic medication and decongestant nasal spray only [44]. After $2-3 w k$, the treatment efficacy rate in the control group was $56.8 \%$, which was significantly lower compared to $86.5 \%$ in the treatment group [44].

In a 2-wk study by Li [45], 79 patients (age: 7-59y) received a combination of ephedrine nasal drops, microwave treatment, Eustachian tube dilation, tympanic puncture, fluid aspiration, 
and optional surgery. The treatment subgroup (40 patients) also received ELOM-080 (300 mg, 3-4 times daily; half the dosage for children). Assessment of audiometry parameters and of symptoms like aural fullness, tinnitus and hearing loss revealed a total efficacy of $90.4 \%$ in the treatment group and of $81.7 \%$ in the control group [45]. A similarly high efficacy of $87.2 \%$ was obtained for patients (age: 7-65) treated for 2 wk with a combination of ELOM080 (300 mg, 3 times daily; half the dosage for children) and budesonide nasal spray [46]. As basal therapy, this treatment group (40 patients) and also the control group (35 patients) received cefaclor ( $250 \mathrm{mg}$, 3 times daily), prednisone $(0.5 \mathrm{mg} / \mathrm{kg}$ bodyweight per day), and optional ephedrine nasal drops. The efficacy, which was judged by the assessment of aural fullness, hearing loss, and tinnitus, was $69 \%$ in the control group and $87.2 \%$ in the treatment group. Furthermore, patients' tympanograms improved to type A in $72 \%$ of all cases in the treatment group [46].

Microwave treatment in combination with ELOM-080 (300 mg, 3 times daily) and a basic medication consisting of antibiotics, prednisone, furosemide, and serrapeptase was used for the treatment of otitis media in 90 patients (mean age: $20.2 \mathrm{y}$ ). A high efficacy of $98.3 \%$ was observed in the treatment group (45 patients) [47]. In contrast, symptoms improved in only $78 \%$ of patients who received basic medication only (45 patients) [47].

In the clinical trial performed by Gu et al. [48], 101 children (age: 5-13y) suffering from acute suppurative otitis media received a routine treatment with intravenously administered penicillin (200 $000 \mathrm{U} / \mathrm{kg}$ bodyweight per day) for $1 \mathrm{wk}$. The treatment group (50 patients) additionally received ELOM-080 (children under $10 \mathrm{y}: 120 \mathrm{mg}$, 3 times daily; children above $10 \mathrm{y}: 300 \mathrm{mg}$, 3 times daily). The follow-up time for all patients was half a year. Effects on the patients' tympanic membrane hyperemia, ear pain, aural fullness, and tympanograms were assessed. The add-on medication with ELOM-080 resulted in a slightly higher total efficacy rate (96.5\% vs. $90.9 \%$ ) and a more pronounced improvement of tympanogram peak pressure. Furthermore, tympanic membrane hyperemia disappeared significantly faster in the treatment group ( $2.5 \pm 0.5 \mathrm{~d})$ than in the control group ( $5.5 \pm 1.5 \mathrm{~d})$, and the relapse rate within the follow-up time was lower ( 3 ears in the treatment group vs. 17 ears in the control group) [48].

\section{Preventive Action of ELOM-080 Treatment}

Apart from the therapeutic treatment of diseases, 2 clinical studies tested whether ELOM-080 can exert preventive actions against otitis media after radiotherapy for nasopharyngeal carcinoma or supports the healing process of patients recovering from sinus surgery due to chronic sinusitis.

He et al. [49] studied the efficacy of ELOM-080 in the prevention of secretory otitis media in 60 patients (age: $30-80 \mathrm{y}$ ) who had undergone radiotherapy as treatment against nasopharyngeal carcinoma. Whereas the control group (30 patients) was not medicated, patients of the experimental group received ELOM080 (300 mg, 3 times daily) for 3 mo. The follow-up time was $1 \mathrm{y}$. The number of cases with otitis was significantly reduced in the treatment group (23.3\%) compared to the control (56.7\%) and correlated with less cases of tinnitus and aural fullness. Additionally, the comparison of the air conduction hearing threshold be- fore and after 3 mo yielded a significantly better hearing in ELOM-080 treated patients [49]. At the beginning of the trial, the mean air conduction hearing threshold was $7.5 \pm 2.0 \mathrm{~dB}$ hearing level $(\mathrm{HL})$ in the experimental group and $8.3 \pm 4.0 \mathrm{~dB} \mathrm{HL}$ in the control group. At the end of the trial, the values changed to $25.6 \pm 3.0 \mathrm{~dB} \mathrm{HL}$ in the experimental group and $40.7 \pm 5.0 \mathrm{~dB} \mathrm{HL}$ in the control group.

In a study by Yan and Yang [50], 167 patients (age: 12-69y) who had undergone endoscopic sinus surgery due to chronic sinusitis received cefmetazole intravenously $4 \mathrm{~d}$ prior and 1 -wk post-surgery. Subsequently, antibiotic treatment was continued by oral administration for $2 \mathrm{wk}$. A fluticasone nasal spray and saline nasal irrigation were applied for a total period of $3 \mathrm{mo}$. In addition to this basal therapy, 1 group ( 84 patients) was treated with ELOM-080 (300 mg, 3 times daily) from day 3 prior until 8 wk after the surgery. Endoscopic examinations were carried out to judge the nasal cavities' condition regarding cleanness and epithelialization. The cavities were clean in $91.7 \%$ of ELOM-080-treated patients compared to $68.7 \%$ of control patients. Furthermore, ELOM-080 caused a higher degree of epithelialization (59.5\%) compared to the control treatment (42.2\%) after $12 \mathrm{wk}$ [50].

\section{Side Effects of ELOM-080}

The review consists of 25 clinical and observational studies including 2412 patients in total. ELOM-080 capsules were administered in 1235 patients (51.2\%). In general, ELOM-080 was well tolerated and the duration of exposure lasted from $2 \mathrm{wk}$ in acute indications up to 3 mo in chronic diseases. In 10 articles, no safety data were reported. This may indicate that there were at least no noticeable safety findings. In 8 further studies with 938 patients (among them 470 ELOM-080-treated patients), it was explicitly stated that no adverse drug reactions (ADR) were observed. ADR were reported in the remaining 7 studies with an exposure of 616 patients in total and 319 patients (51.8\%) in the ELOM-080 group. In 1 study [30], only the numbers of ADR (ELOM-080: 4 cases; control: 3 cases) were reported, but not specified. In the ELOM-080 group 28 ADR in 24 patients and in the control group 15 ADR in 14 patients were reported. All adverse drug reactions were nonserious and expected; no new or unexpected adverse events were identified. In the ELOM-080 group 22/28 (78.6\%) ADR and in the control group $7 / 15$ (46.7\%) ADR referred to the system organ class of gastrointestinal diseases and are listed below:

- Nausea: 9 cases in 5 studies in the ELOM-080 groups; 3 cases in 2 studies in the control groups

- Abdominal pain/discomfort: 7 cases in 4 studies in the ELOM080 groups; 3 cases in 2 studies in the control groups

- Vomiting: 2 cases in 1 study in the ELOM-080 group; no case in the control group

- Taste alterations: 3 cases in 1 study in the ELOM-080 group; no case in the control group

- Poor appetite: 1 case in the ELOM-080 group; 1 case in 1 study in the control group

Additionally, single cases of rash (ELOM-080: 1 case in 1 study), dizziness (ELOM-080: 1 case and control: 1 case in 1 study), and sleepiness (ELOM-080: 0 cases and control: 4 cases in 1 study) 
were reported. All ADR recovered within the treatment phase. These data were in accordance to the expected ADR profile reported in European studies, which have already documented the good tolerability of ELOM-080.

\section{Investigations into the Mode of Action of ELOM-080}

The influence of ELOM-080 on mucociliary clearance in vivo was at first demonstrated in a pilot study by German researchers [9] and has been recently updated in vitro by another research group [7]. Interestingly, it is the great merit of several Chinese research groups to provide an in depth understanding of the mode of action and to characterize ELOM-080 as an enhancer of the mucociliary clearance [25,55-57]. These Chinese research groups investigated the mode of action of ELOM-080 using different in vitro techniques. The respective data are presented below and discussed in the context of previously reported data sets applying comparable methods.

\section{Ciliary beat frequency}

ELOM-080 $(250 \mathrm{ng} / \mathrm{mL})$ was found to increase the ciliary beat frequency (CBF) of nasal epithelial cells isolated from healthy subjects, COPD patients, and bronchiectasis patients after $4 \mathrm{~h}$ of incubation at $37^{\circ} \mathrm{C}$ [57]. A more detailed study revealed that ELOM080 only effects CBF and chloride secretion when it is applied from the basolateral site and also observed a concentration-dependent effect taking into account that the applied concentrations were significantly higher compared to the previous studies [25]. With reference to the basolateral site instead of apical applications, it is necessary to emphasize that in clinical settings the basolateral pathway is clinically more relevant, because it mirrors the hematogenic distribution of ELOM-080 [55]. Interestingly, studies in human sinonasal explants grown in submersion showed no effects of ELOM-080 in concentrations lower than the therapeutic concentration on $\mathrm{CBF}$ when examined at $23^{\circ} \mathrm{C}$ [58]. These responses of CBF to ELOM-080 exposure highlight the need to standardize the experimental conditions of in vitro studies in order to obtain reliable data. Nevertheless, ELOM-080 triggered a higher CBF of cilia when applied at therapeutically relevant concentrations (up to $300 \mathrm{ng} / \mathrm{mL}$ ) and the effect was most pronounced when experimental test temperatures mimic conditions prevailing in the respiratory tract $[59,60]$.

\section{Epithelial fluid secretion}

In addition to stimulating CBF, it was shown that ELOM-080 is a potent stimulant of respiratory epithelial fluid secretion as evidenced by the increase in airway surface liquid height [25]. This underlines that mucus hydration is paramount for normal mucociliary clearance. Li et al. [56] demonstrated in human nasal epithelial cells that ELOM-080 enhances the mucus production from goblet cells in the short-term and promotes ciliated cell differentiation in the long-term.

\section{Mucociliary clearance}

Studies testing effects of ELOM-080 on the parameter mucociliary clearance (MCC), which integrates CBF and fluid secretion, provided a consistent, significant effect [7]. Most measurements were performed in vivo and confirmed the clinical relevance of experimental results. Following $10 \mathrm{~d}$ of treatment with ELOM-080 (300 mg, 3 times daily) in 12 patients with rhinitis, mucociliary transport time quantified by using the saccharine test was shortened from $12.8 \pm 4.5 \mathrm{~min}$ to $9.3 \pm 3.8 \mathrm{~min}$ [55]. Similarly, Han et al. [58] tested effects of ELOM-080 (300 mg, 3 times daily for $10 \mathrm{~d})$ on MCC in patients with chronic rhinitis in comparison to an untreated control group. Whereas mucociliary transport time remained unchanged in the control group, it improved significantly in response to ELOM-080 treatment from $883 \pm 61 \mathrm{~s}$ to $715 \pm 63 \mathrm{~s}$ [58]. These in vivo data were also supported by data obtained in cell culture. Whereas $0.05 \%$ ELOM-080 had no effect, $0.1 \%$ stimulated mucociliary clearance by $46 \pm 16 \%$ compared to an untreated control [25].

\section{Summary and Conclusion}

This review summarizes clinical studies on ELOM-080 as add-on treatment in various diseases of the human respiratory tract published in the Chinese medical literature. So far, these studies were largely neglected in the evaluation of the clinical efficacy of ELOM080 as they were not published in English and internationally referenced journals. Besides the well-established and approved indications sinusitis and bronchitis, the reviewed studies suggest that ELOM-080 might have a therapeutic potential against diseases that have not been investigated in clinical studies before: in particular, a considerable number of studies showed a high efficacy of ELOM-080 in the add-on treatment of otitis media. Moreover, this review increases the number of publications on the mode of action of ELOM-080 regarding its action on the mucociliary clearance. In conclusion, the newly available information supports earlier results showing that ELOM-080 represents an effective and safe phytotherapeutical strategy for the treatment of respiratory tract diseases.

\section{Conflict of Interest}

Two of the authors (JT and TW) are employees of the company that manufactures ELOM-080.

References

[1] Kash JC, Taubenberger JK. The role of viral, host, and secondary bacterial factors in influenza pathogenesis. Am J Pathol 2015; 185: 1528-1536

[2] Bosch AA, Biesbroek G, Trzcinski K, Sanders EA, Bogaert D. Viral and bacterial interactions in the upper respiratory tract. PLoS Pathog 2013; 9: e1003057

[3] Harris AM, Hicks LA, Qaseem A. Appropriate antibiotic use for acute respiratory tract infection in adults: advice for high-value care from the American College of Physicians and the Centers for Disease Control and Prevention. Ann Intern Med 2016; 164: 425-434

[4] Ciprandi G, Caimmi D, Miraglia Del Giudice M, La Rosa M, Salpietro C, Marseglia GL. Recent developments in united airways disease. Allergy Asthma Immunol Res 2012; 4: 171-177 
[5] Halbert RJ, Natoli JL, Gano A, Badamgarav E, Buist AS, Mannino DM. Global burden of COPD: systematic review and meta-analysis. Eur Respir । 2006; 28: 523-532

[6] Liu W, Huang C, Hu Y, Fu Q, Zou Z, Sun C, Shen L, Wang X, Cai J, Pan J, Huang Y, Chang J, Sun Y, Sundell J. Associations of gestational and early life exposures to ambient air pollution with childhood respiratory diseases in Shanghai, China: a retrospective cohort study. Environ Int 2016; 92-93: 284-293

[7] Begrow F, Böckenholt C, Ehmen M, Wittig T, Verspohl EJ. Effect of Myrtol standardized and other substances on the respiratory tract: ciliary beat frequency and mucociliary clearance as parameters. Adv Ther 2012; 29: 350-358

[8] Gillissen A, Wittig T, Ehmen M, Krezdorn H, de Mey C. A multi-centre, randomised, double-blind, placebo-controlled clinical trial on the efficacy and tolerability of GeloMyrtol forte in acute bronchitis. Drug Res 2013; 63: 19-27

[9] Kaschke O, Behrbohm H, Sydow K. The influence of a secretolytic drug on mucociliary clearance of the maxillary sinus. J Rhinol 1997; 4: 29-33

[10] Rantzsch U, Vacca G, Duck R, Gillissen A. Anti-inflammatory effects of Myrtol standardized and other essential oils on alveolar macrophages from patients with chronic obstructive pulmonary disease. Eur J Med Res 2009; 14 (Suppl. 4): 205-209

[11] Grassmann J, Hippeli S, Dornisch K, Rohnert U, Beuscher N, Elstner EF. Antioxidant properties of essential oils. Possible explanations for their anti-inflammatory effects. Arzneimittelforschung 2000; 50: 135-139

[12] Beuscher N, Kietzmann M, Bien E, Champeroux P. Interference of Myrtol standardized with inflammatory and allergic mediators. Arzneimittelforschung 1998; 48: 985-989

[13] Beuscher N, Bien E, Elstner E, Kietzmann M, Amon U. Myrtol standardized in treatment of sinusitis and bronchitis - pharmacodynamics and pharmacokinetics. Z Phytother 1997; 8: 9-10

[14] App EM. Stellenwert der Mukusclearance für das Bronchialsystem - Pathophysiologie und therapeutische Ansätze. In: Meister R, ed. Entzündliche Erkrankungen des Bronchialsystems - Ergebnisse der II. Sylter Sekretolyse-Gespräche. Heidelberg: Springer; 2000: 27-53

[15] Fokkens W], Lund VJ, Mullol ], Bachert C, Alobid I, Baroody F, Cohen N, Cervin A, Douglas R, Gevaert P, Georgalas C, Goossens H, Harvey R, Hellings P, Hopkins C, Jones N, Joos G, Kalogjera L, Kern B, Kowalski M, Price D, Riechelmann H, Schlosser R, Senior B, Thomas M, Toskala E, Voegels R, Wang de Y, Wormald PJ. European position paper on rhinosinusitis and nasal polyps 2012. Rhinol Suppl 2012; 23: 1-298

[16] DEGAM. Deutsche Gesellschaft für Allgemeinmedizin und Familienmedizin Leitline Nr. 11 Husten. Available at https://www.awmf.org/uploads/ tx_szleitlinien/053-013I_S3_Husten_2014-02-abgelaufen.pdf. Accessed December 10, 2018

[17] Abholz HH, Gillissen A, Magnussen H, Schott G, Schultz K, Ukena D, Worth $\mathrm{H}$. Nationale VersorgungsLeitlinie COPD. Available at https:// www.leitlinien.de/mdb/downloads/nvl/copd/archiv/copd-vers1.9-lang. pdf. Accessed December 10, 2018

[18] Kardos P, Dinh QT, Fuchs KH, Gillissen A, Klimek L, Koehler M, Sitter H, Worth $\mathrm{H}$. Guidelines of the German Respiratory Society for diagnosis and treatment of adults suffering from acute, subacute and chronic cough. Pneumologie 2019; 73: 143-180

[19] Stuck B, Bachert C, Federspiel P, Hosemann W, Klimek L, Mösges R, Pfaar O, Rudack C, Sitter H, Wagenmann M, Weber R, Hörmann K. S2-Leitlinie Rhinosinusitis - Langfassung. HNO 2012; 60: 141-162

[20] Stuck BA, Beule A, Jobst D, Klimek L, Laudien M, Lell M, Vogl T, Popert U S2k-Leitlinie Rhinosinusitis. Available at https://www.awmf.org/uploads/ tx_szleitlinien/017-049_und_053-012l_S2k_Rhinosinusitis_2019-04. pdf. Accessed January 8, 2019

[21] Vogelmeier C, Buhl R, Criée C, Gillissen A, Kardos P, Köhler D, Magnussen $\mathrm{H}$, Morr H, Nowak D, Pfeiffer-Kascha D. Leitlinie der Deutschen Atemwegsliga und der Deutschen Gesellschaft für Pneumologie und Beatmungsmedizin zur Diagnostik und Therapie von Patienten mit chronisch obstruktiver Bronchitis und Lungenemphysem (COPD). Pneumologie 2007; 61: e1-e40

[22] Poole PJ, Black PN. Oral mucolytic drugs for exacerbations of chronic obstructive pulmonary disease: systematic review. BMJ 2001; 322: 1271 1274

[23] Smith SM, Fahey T, Smucny ], Becker LA. Antibiotics for acute bronchitis. Cochrane Database Syst Rev 2014; (6): CD000245

[24] Poole P, Chong J, Cates C]. Mucolytic agents versus placebo for chronic bronchitis or chronic obstructive pulmonary disease. Cochrane Database Syst Rev 2015; (7): CD001287

[25] Lai Y, Dilidaer D, Chen B, Xu G, Shi J, Lee RJ, Cohen NA. In vitro studies of a distillate of rectified essential oils on sinonasal components of mucociliary clearance. Am J Rhinol Allergy 2014; 28: 244-248

[26] Zhang QS, Cheng XL, Yang B. Efficacy of Myrtol standardized adjuvant therapy in chronic pharyngitis. Hainan Medical Journal 2009; 20: 87-88

[27] Chen DZ. GeloMyrtol in the treatment of chronic sinusitis in children: a clinical observation study. Sichuan Medical Journal 2004; 25: 806-807

[28] Nai HY, Li Y, Bi JL. The therapeutic effects of GeloMyrtol on children's chronic nasosinusitis - a report of 85 cases. Journal of Nanhua University 2008; 36: 370-371

[29] Zhou GF, Yang LP, Shi J. Therapeutic effect of azithromycin with GeloMyrtol in the treatment of pediatric chronic sinusitis: an observational study. Journal of Dali University 2010; 9: 47-48

[30] Li Q. Efficacy of azithromycin in combination with GeloMyrtol in the treatment of chronic sinusitis in children. Chinese Journal of Rational Drug Use 2014; 7: 64-65

[31] Wu Y, Tang J. Therapeutic effects of Myrtol standardized enteric soft capsules in the treatment of pediatric chronic sinusitis. Journal of Clinical Medicine in Practice 2011; 15: 86-87

[32] Xia XR, Ning JL, Wu CY, Shen H, Liu YL. GeloMyrtol in the treatment of post-nasal drip syndrome: a clinical analysis of 78 cases. Jiujiang Medical Journal 2008; 23: 86-87

[33] Chen GM, Chen XY. Therapeutic effect of GeloMyrtol in the treatment of sinusitis of 80 patients: an observational study. Journal of Guangdong Medical College 2001; 19: 146

[34] Li S, Xie JH, Zhang Y, Than WZ. Efficacy of GeloMyrtol in the treatment of acute bronchitis and asthmatic bronchitis in children (a clinical observational study). Journal of Pediatric Pharmacy 2004; 10: 36-37

[35] Zhang CM, Zhang HL. Therapeutic effects of GeloMyrtol in the treatment of 34 child patients with recurrent bronchitis. Clin Med (Northfield II) $2002 ; 22: 33-34$

[36] Gao WH. Efficacy of GeloMyrtol in the treatment of acute exacerbations of chronic bronchitis (AECB): an observational study. Journal of Practical Diagnosis and Therapy 2008; 22: 459-460

[37] Gan LP, Cao ZQ. GeloMyrtol in the treatment of acute exacerbations of chronic bronchitis in 30 patients. Jiangxi Medical Journal 2009; 44: 782-783

[38] Xu F, Wu ZQ. The application of Myrtol standardized enteric coated soft capsules on acute chronic obstructive pulmonary disease. Sichuan Medical Journal 2009; 30: 539-540

[39] Wen YT. Effects of Myrtol standardized in the treatment of acute exacerbation of chronic obstructive pulmonary disease. Medicine Healthcare Apparatus 2011; 18: 540-541

[40] Gao XY, Hao PZ. Expectorant ancillary therapy for acute asthma in children: an analysis of 38 cases. Journal of Pediatric Pharmacy 1998; 4: 3334

[41] Chen K. Myrtol in the adjuvant treatment of secretory otitis media with type $\mathrm{C}$ tympanograms. Chinese Journal of New Drugs and Clinical Remedies 2002; 21: 280-282

[42] Yu LX, Zhang XF. Clinical observation of GeloMyrtol in the treatment of secretory otitis media. Journal of Qiqihar Medical College 2002; 23: 900 
[43] Zhou H]. Clinical efficacy of GeloMyrtol in the treatment of secretory otitis media. Journal of Zhejiang College of Traditional Chinese Medicine 2001; 25: 41

[44] Tang GF, Wang SX. Observation of therapeutic effects of Myrtol standardized and Budesonide on secretory otitis media. China Journal of Modern Medicine 2006; 16: 2363-2364

[45] Li XM. The analysis of the therapeutic effect of microwave-assisted GeloMyrtol treatment in secretory otitis media. Heilongjiang Medicine Journal 2008; 21: 90-92

[46] Xue QQ, Chen Z], Bai GP. Therapeutic effects of Myrtol standardized combined with budesonide in the treatment of secretory otitis media. China Pharmacist 2009; 12: 1004-1005

[47] Zhang J. Efficacy of microwaves in combination with GeloMyrtol in the treatment of acute secretory otitis media. Chinese Journal of Modern Drug Application 2011; 5: 185-186

[48] Gu Y, Xiao L, Zhu LY. Myrtol adjuvant therapy in 50 children with acute suppurative otitis media. Chinese Journal of Ophthalmology and Otorhinolaryngology 2011; 11: 113

[49] He J, Wu P, Wu-Su RN, Mirikamili K, Yu SF, Liao LF, Quan HT, Zhang S, Tang YY. Clinical efficacy of Myrtol standardized capsules in the prevention of secretory otitis media after radiotherapy for nasopharyngeal carcinoma. Journal of Clinical Otorhinolaryngology Head Neck Surgery 2013; 27: 473-474

[50] Yan JM, Yang Y]. Application of GeloMyrtol in the perioperative period of endoscopic sinus surgery. Zhejiang Clinical Medical Journal 2005; 7: 629

[51] Liu LL, Chen LJ, Zhan M, Hu ZB, Lu HB. Myrtol standardized in the treatment of chronic bronchitis and COPD: a systematic review. China Pharmacy 2012; 23: 1496-1500
[52] Zhang XX, Shi T, Nie XH. Systematic review on Myrtol standardized in the treatment of chronic obstructive pulmonary disease. China Pharmaceuticals 2013; 22: 36-39

[53] Zhang Y, Zhou S. Standardized Myrtol in the treatment of secretory otitis media: a systematic review. West China Medical Journal 2013; 28: 56-58

[54] Zhang XX, Shi T, Nie XH. Systematic review on Myrtol standardized in the treatment of chronic obstructive pulmonary disease. China Pharmaceuticals 2013; 22: 36-39

[55] Wang H, Han DM, Song XH, Zhang W, Zhang L. Effects of Myrtol standardized on human nasal mucociliary transport. Journal of Capital Medical University 2009; 30: 62-65

[56] Li YY, Liu ], Li CW, Subramaniam S, Chao SS, Yu FG, Cohen NA, Li S, Wang DY. Myrtol Standardized affects mucociliary clearance. Int Forum Allergy Rhinol 2016; 7: 304-311

[57] Kwok PW. The effects of GeloMyrtol forte on human ciliary beat frequency and intracellular cyclic adenosine monophosphate in vitro (master's thesis). Available at http://hdl.handle.net/10722/131697. Accessed December 15, 2018

[58] Han D, Wang N, Zhang L. The effect of Myrtol standardized on human nasal ciliary beat frequency and mucociliary transport time. Am J Rhinol Allergy 2009; 23: 610-614

[59] Mercke U, Hakansson CH, Toremalm NG. The influence of temperature on mucociliary activity. Temperature range 20 degrees $C-40$ degrees $C$. Acta Otolarnygol 1974; 78: 444-450

[60] Green A, Smallman LA, Logan AC, Drake-Lee AB. The effect of temperature on nasal ciliary beat frequency. Clin Otolaryngol Allied Sci 1995; 20: $178-180$ 